\title{
A ENFERMAGEM NO PROJETO DE COOPERAÇÃO EDUCACIONAL VILA PARANOÁ
}

\author{
* Kazue Horigoshi Rodrigues \\ ** Maria da Glória Miotto Wright \\ *** Wanda Polewacz Mahajan
}

$\operatorname{ReBEn} /() 7$

Rodrigues K.H. e Colaboradoras - A Enfermagem no Projeto de Cooperação Educacional Vila Paranoá. Rev. Bras. Enf.; RS.36: 183 - 192, 1983.

\section{INTRODUÇÃO}

O mercado de trabalho tem determinado a formação e a utilização de recursos humanos na área de saúde. Desta maneira os currículos dos cursos de graduação em enfermagem tem oferecido experiências de ensino-aprendizagem predominantemente no âmbito hospitalar tornando-se muitas vezes, raras as visitas às comunidades para o conhecimento das circunstâncias em que vive a população.

Por outro lado a política atual do setor saúde tem mostrado a necessidade de extensão de cobertura dos serviços de saúde e o emprego da assistência primária e participação comunitária como uma estratégia para atingir a este objetivo.

A questão com que deparamos é, como manter um equilíbrio do ensino e como introduzir o novo modelo de formação do profissional de enfermagem para desempenhar o papel exigido nestes programas. A formação e o treinamento apropriado à extensão de cobertura exigem crescente articulação entre o ensino e a prestação de serviços, possibilitando a criação de abordagens inovativas para atender as reais necessidades de saúde das comunidades, assim como uma postura firme quanto a participação firme do enfermeiro nos diferentes níveis de assistência principalmente na assistência primária.

Segundo Paim e Colab (78) uma inovação que se ousa propor se prende ao fato de que para assumir a assistência primária de saúde como responsabilidade de todos os profissionais desta área exigiria do aspecto de formação em período curricular comum a todos os cursos de saúde, onde todos os estudantes da área ou centros juntos, experimentassem participar dos programas de extensão de cobertura de saúde em atividades com características de assistência primária.

O modelo de assistência de enfermagem voltado para a comunidade está se tornando uma realidade no atual sistema de prestação de serviços de saúde na cidade de Brasília; apesar de que um grande contingente de enfermeiros ainda seja absorvido para atuar a nível hospitalar.

Tem-se debatido a formação de um enfermeiro generalista, preparado para prestar assistência integral ao cliente (indivíduo, famíiia e comunidade), onde inclua ações de promoção, proteção, e recuperação de saúde. Com um intuito de oferecer um ensino muito mais de cunho realístico, o Curso de Enfermagem da UnB mobilizou-se no sentido de desenvolver programas de saúde comunitária em área peri-urbana. Tais programas não só oferecem aos docentes e discentes e técnicos a oportunidade de trabalho em uma problemática de saúde não distorcida artificialmente, mas constitui a base de futuras inovações no ensino e na assistência de saúde. Mediante a colocação acima, este trabalho visa expor a experiência da Universidade de Brasília, através do Curso de Enfermagem, na implantação de um Projeto que procura desenvolver um modelo de assistência à saúde com real participação comunitária e com ensino baseado neste modelo.

2. O Projeto de Cooperação Educacional - Vila Paranoá:

\subsection{Antecedentes:}

Considerando-se a situação de mudança das atividades docentes e assistenciais da Faculdade de Ciências da Saúde da UnB, da Unidade Integrada de Saúde de Sobradinno para

\footnotetext{
* Professora da Disciplina de Enfermagem Pediátrica - UnB;

** Professora das Disciplinas de Metodologia do Processo de Enfermagem e Enfermagem de Saúde da Comunidade - UnB. Aluna Regular do Curso de Doutorado em Enf. USP;

*** Professora da Disciplina de Enfermagem Gineco-Obstétrica - UnB.
} 
Rodrigues K.H. e Colaboradoras - A Enfermagem no Projeto de Cooperação Educacional Vila Paranoá. Rev. Bras. Enf.; RS.36: 183 - 192, 1983.

o Hospital Presidente Médici (INAMPS), o Curso de Graduação em Eṇfermagem sentiu a necessidade de promover um trabalho de Saúde da Comunidade.

O Curso de Enfermagem vem utilizando como campo de estágio além do Hospital Presidente Médici, a rede Hospitalar do Distrito Federal e os Postos de Saúde da Secretaria de Saúde. Considerando a necessidade de diversificar as experiências do aluno num trabalho direto com a comunidade, o "Projeto de Cooperação Educacional - Vila do Paranoá" passou a integrar como campo de estágio para os alunos das seguintes disciplinas: Introdução à Saúde Pública, Enfermagem em Saúde da Comunidade, Enfermagem Pediátrica, Enfermagem GinecoObstétrica, Metodologia do Processo de Enfermagem, Didática Aplicada à Enfermagem, Enfermagem na Saúde do Escolar.

Diante das perspectivas que o Curso de Graduação em Enfermagem se propunha, o Curso de Nutrição da UnB interessou-se também em participar do projeto, oferecendo a sua contribuição através das seguintes disciplinas: Nutrição em Saúde Pública, Nutrição MaternoInfantil e Estágio Supervisionado em Nutrição.

\subsection{Características Gerais do Projeto:}

A Legião Brasileira de Assistência já vinha desenvolvendo atividades de Assistência e Promoção à Saúde na Invasão do Paranoá através do seu Centro Social. Em fins de 1979 iniciaram-se os primeiros contatos com a LBA com a finalidade de firmar um Convênio FUB/LBA na tentativa de se estabelecer uma Cooperação Educacionàl entre as duas instituições para o benefício da Comunidade.

Este projeto se propunha a estabelecer:

a) Uma assistência de saúde à mãe, à criança e à comunidade através de um serviço de baixo custo, integrando recursos da UnB através dos Cursos de Enfermagem e Nutrição com o Centro Social da LBA, Comunidade da Invasão do Paranoá e Serviços de Saúde do D. F. (Postos de Saúde);

b) Diversificação de experiências na formação acadêmica do corpo discente através de um contato maior com a realidade para identificar problemas e situações que levariam ao planejamento de atividades de acordo com os recursos e prioridades das famílias e da comunidade, além de dar a oportunidade de um trabalho em equipe multidisciplinar e multinstitucional;

c) Oferecer subsídios para o desenvolvimento de pesquisas científicas em áreas prioritárias de saúde de acordo com plano de desenvolvimento do país.

2.3. Objetivos:

2.3.1. Objetivos Gerais:

Estabelecer Cooperação Educacional entre duas instituições FUB/ensino) e LBA (assistência) para benefício da comunidade e dar uma visão de assistência a nível primário para o corpo discente;

2.3.2. Objetivos Específicos:

- Desenvolver diagnóstico de Saúde da Comunidade;

- Proporcionar assistência de Saúde à mãe e a criança;

- Desenvolver educação em saúde $\mathrm{p} /$ grupos específicos da comunidade;

- Desenvolver um trabalho de "descoberta de parteiras curiosas" para orientação, treinamento e supervisão de suas atividades como agentes de saúde dentro da comunidade;

- Desenvolver trabalhos de pesquisa nas áreas de Nutrição e Enfermagem a nível de comunidade;

- Desenvolver diagnóstico nutricional da comunidade.

3. Atividades Realizadas:

3.1. Período: $01 / 81$ e $02 / 81$

3.2. Saúde da Comunidade: Vila do Paranoá - aspectos históricos, características e diagnóstico da Comunidade: 
Rodrigues K.H. e Colaboradoras - A Enfermagem no Projeto de Cooperação Educacional Vila Paranoá. Rev. Bras. Enf.; RS.36: 183 - 192, 1983.

Distando $26 \mathrm{Km}$. do Plano Piloto, a Vila do Paranoá está localizada próximo à barragem do Lago Paranoá, existindo desde 1957, com a construção do acampamento para execução das obras da barragem.

Como o acampamento não possuia alojamento para operários casados, houve autorização da construtora para que fossem erguidos barracos, junto ao acampamento para abrigo das familias.

A Comunidade do Paranoá se divide em dois núcleos principais, sendo o primeiro o chamado "antigo acampamento dos construtores da barragem", e o segundo, a "Invasão propriamente dita", que se subdivide em "Vila Piauî" e "Vila do Paranoá".

Com o término das obras da barragem, a Vila assumiu uma nova feição que a caracteriza como favela, conseqüentemente pobre e desprovida de recursos básicos.

A população é oriunda, em quase sua totalidade dos Estados de Minas Gerais, Goiás, Bahia, Maranhão, Ceará e Piauí, resindindo em barracos de madeiras, em condições subhumanas, onde a prosmicuidade é uma constante.

A Vila do Paranoá não oferece oportunidade de trabalho, obrigando seus moradores a se deslocarem para o Plano Piloto, tornando-se apenas uma vila dormitório.

Para estabelecer as características e o diagnóstico da comunidade utilizou-se instrumentos de coleta de dados, com os quais foram levantados dados relativos à comunidade e 61 famílias.

O levantamento realizado revelou que a falta de infra-estrutura de serviços básicos é sentida e reclamada pela população que não dispõe de rede de esgoto, uma vez que não fazem parte do Plano Diretor de Brasília, e os órgãos oficiais nela não atuam. Alguns barracos, próximos ao antigo acampamento possuem rede de água mas sem tratamento indispensável para ser consumida. Todos os barracos são servidos de luz elétrica.

Quanto ao meio de transporte existem 3 linhas de ônibus: uma delas ligando a Vila ao Núcleo Bandeirante e as outras duas comunicando-a com o Plano Piloto - uma pela Asa Sul outra pela Asa Norte. O problema identificado em relação ao transporte se refere aos intervalos de saída dos ônibus que é de hora em hora, prejudicando muito as atividades dos que trabalham fora.

$\mathrm{O}$ comércio está situado na área central da Vila, havendo predominância no ramo de gêneros alimentícios. A localização dos barracos não obedeceram a nenhum critério de delimitação de área ou de lote e nem definição de rua ou praça, sendo que existiam 17 ruas identificadas pelos moradores, que foram os que deram as denominações e numerações mas num sistema criado por eles próprios e ao qual só eles tem acesso pois não há placas nem sinais. Recentemente a Terracap numerou todos os barracos existentes.

Outro aspecto identificado foi que, o elemento masculino engaja-se sempre na construção civil e jardinagem, por não apresentar qualificação profissional, advindo dessa forma a baixa renda familiar. As mulheres exercem, na maioria das vezes, atividades como domésticas, babás e faxineiras.

Um aspecto a ser ressaltado é o alheiamento da população sobre o aspecto de higiene, agravado pela presença de lixo nas ruas, animais soltos, falta de esgoto, de fossas e de água.

A situação jurídica da família revelou-se bastante irregular com um número elevado de mães solteiras e abandono do chefe de familia. A prostituição se faz sentir de maneira marcante, principalmente em menores segundo informações de professores da Unidade Escolar local.

No que se refere ao lazer, são poucas as oportunidades e as raras que surgem são oferecidas pela instalação esporádica de parques infantis e circos de pequeno porte. $O$ número de menores ociosos perambulando ou jogando bola é grande, fato este que traz preocupação para os pais que não sabem o que fazer com os filhos.

No que diz respeito à saúde da população, podemos considerar como característica principal a carência ampla de serviços básicos de nutrição e saúde. A população conta apenas com um ambulatório o "Centro Social São Geraldo de Assistência Materna-Infantil funcionando apenas às 2 ? 's feiras. Além de ser precário atende apenas uma faixa da população, precisan- 
Rodrigues K.H. e Colaboradoras - A Enfermagem no Projeto de Cooperação Educacional Vila Paranoá. Rev. Bras. Enf.; RS.36: 183 - 192, 1983.

do os demais a saírem da Vila em caso de doença. Duas vezes por mês a Comunidade recebe atendimento em relação a Imunização através da Secretaria de Saúde.

A partir de março de 81 estão também atuando as professoras e alunos da UnB fazendo atendimento na Ârea Materna-Infantil. Quanto ao aspecto nutricional as famílias apresentam uma dieta qualificativa e quantitativa abaixo do recomendado. Com a intenção de melhorar o estado nutricional de gestantes, nutrizes e menores o Centro Social do Paranoá desenvolve o "Programa de Complementação Alimentar (PCA) com distribuição de leites, vitaminas e sopas.

No setor educacional existe apenas uma escola de $1^{\circ}$ grau que não responde à demanda da população assim como a inexistência de educação de $2^{\circ}$ grau obriga uma ampla faixa de indivíduos a procurarem escolas no Plano Piloto.

Em relação à Educação do Pré-Escolar, o Centro Social do Paranoá mantém atendimento a pré-escolares sob forma de creche "Casulo" assistindo a 210 crianças em dois períodos de 4 horas. O Projeto "Elo" para escolares de 7 a 18 anos atende a um total de 81 indivíduos fornecendo reforço alimentar e atividades escolares diariamente.

3.3. Saúde Materna: características gerais da população materna e programação proposta:

As características gerais da população feminina em idade fértil na Vila Paronoá, se reveste de aspectos semelhantes a de qualquer comunidade rural e/ou periférica pobre, onde é grande o número das que deixaram o campo, em busca de melhores condições de vida nos centros urbanos e capitais. A maioria é analfabeta, desempregada ou sub-empregada, em situação indefinida de laços conjugais, dependência sócio-econômica total do companheiro, gestações freqüentes e estado de saúde geral precário.

Sabe-se que a assistência à mãe tem a finalidade de proporcionar a toda mulher um período de gravidez saudável, reduzindo ao mínimo as complicações e permitindo um parto normal, a fim de que dê a luz a um filho sadio, assim como condições para aprender como cuidar de seu filho.

Com a finalidade de proporcionar um atendimento às gestantes e mães que vivem na Vila do Paranoá, se propôs o seguinte programa:

1. Realizar a assistência de enfermagem a todas as gestantes que procuram o serviço através da pré-consulta e da consulta de enfermagem;

2. Desenvolver programas de Educação para a saúde, preparo para o parto e para o aleitamento natural e planejamento familiar, para grupo de gestantes, puérperas e nutrizes;

3. Encaminhar as gestantes, puérperas e/ou nutrizes a outros profissionais da equipe de saúde e/ou outros recursos da comunidade conforme as necessidades detectadas;

4. Participar com outros profissionais da equipe de saúde no planejamento, execução e avaliação de programas da área.

Atividades:

O programa consta das seguintes atividades:

a) Inscrição:

O registro de cliente na Assistência Materna.

- entrevista com a mãe;

- triagem

- agendamento para consulta de Enfermagem.

Elemento Nuclear:

Docente ou Estudante de Enfermagem ou Agente de Saúde da Comunidade.

b) Pré-Consulta:

Compõe-se das seguintes ações:

- identificação da cliente (nome, sexo, idade, filiação; dados sócio-econômicos);

- verificação de sinais vitais, peso e altura;

- registro de dados;

- encaminhamento p/consulta de Enfermagem.

Elemento Nuclear:

Docente ou Estudante de Enfermagem ou Agente de Saúde. 
Rodrigues K.H. e Colaboradoras - A Enfermagem no Projeto de Cooperação Educacional Vila Paranoá. Rev. Bras. Enf.; RS.36: 183 - 192, 1983.

c) Consulta de Enfermagem:

Ações que compõem a consulta da gestante:

- histórico de Enfermagem: análise de prontuário e anamnese: (preenchimento da ficha)

- exame físico e obstétrico;

- identificação de problemas e orientação;

- encaminhamentos (médico, odontólogo, vacinação, Serviço Social, farmácia, exames laboratoriais);

- registro de dados;

- retorno e agendamento p/próxima consulta.

Ações que compõe a Consulta a Puérpera e ao Recém-nascido:

- TPR e PA;

- Peso;

- Exame das mamas; avaliação das condições de lactação;

- Exame do abdomem; avaliação da involução uterina através de palpação e mensuração;

- Observação das condições das cicatrizes cesariana ou episiorrafia;

- Observação dos lóquios (aspecto, cor, quantidade);

- Exame do RN.

Elemento Nuclear:

Docente ou Estudante de Enfermagem ou Agente de Saúde:

d) Educação para Saúde:

- pode ser desenvolvida individualmente ou em grupos formais e informais.

e) Horário de Atendimento:

-2 a feira - 14:00 às 18:00 horas;

- 4. feira - 08:00 às 12:00 horas.

3.4. Saúde Infantil:

3.4.1. Aspectos gerais da população e programação proposta:

Os países em desenvolvimento se caracterizam por apresentar quase $40 \%$ de população jovem ę em alguns locais $1 / 4$ a $1 / 3$ das crianças morrem antes dos 5 primeiros anos de vida, álém disso é preciso considerar os casos de doenças não fatais ocorridas neste períoda e que poderão provocar danos permanentes para a saúde e desenvolvimento.

A experiência realizada em alguns países tem demonstrado que com recursos limitados é possível modificar este quadro através da melhoria do padrão geral de vida, introdução de medidas preventivas e quando os serviços curativos básicos se tornam acessivieis a população infantil.

Considerando-se a "Vila Paranoá" uma comunidade pobre, carente de recursos assistenciais de saúde e com grande população infantil, identificamos a necessidade de um trabalho que se ocupasse da saúde das crianças.

Considerando-se as disponibilidades de recursos humanos e o fato de que a problemas nutricionais e de saúde ocorridos no 1 . a ano de vida são decisivos para o crescimento e desenvolvimento posterior estabeleceu-se para a 1. fase um "Programa de Atendimento para Crianças de 0-1 ano de idade".

População: Crianças de 0 a 1 ano de idade, da Comunidade do Paranoá, cujas famílias estejam matriculadas no programa de assistência da LBA.

Objetivo Geral: Prestar assistência de enfermagem à criança de 0 a 1 ano de idade, inscrita na LBA.

Objetivos específicos:

a) proporcionar consulta de enfermagem à criança sadia de 0 a 1 ano de idade para avaliação de seu crescimento e desenvolvimento;

b) orientar às mães quanto aos problemas encontrados na consulta de enfermagem (alimentação, vacinação, patologias, etc.) e quanto ao ritmo de crescimento e desenvolvimento de seu filho, visando a elevação do nível de saúde da comunidade; 
Rodrigues K.H. e Colaboradoras - A Enfermagem no Projeto de Cooperação Educacional Vila Paranoá. Rev. Bras. Enf.; RS.36: 183 - 192, 1983.

c) encaminhar as mães, cujos filhos apresentam agravos de saúde, ao serviço médico mais próximo (Núcleo Bandeirante), acompanhando-os, posteriormente, em seu tratamento por meio de consultas subseqüentes;

d) fazer visita domiciliária aos faltosos e às crianças que necessitem de assistência de enfermagem no lar.

Atividades: O programa consta das seguintes atividades:

a) Inscrição: É o registro do cliente no programa de saúde, o qual permitirá seu acesso ao serviço de assistência à criança menor de 1 ano.

Composição:

- entrevista com a mãe;

- agendamento para a consulta de enfermagem (19 consultas).

Elemento nuclear:

- assistente social ou estagiária de enfermagem.

Observação:

- o elemento nuclear desta atividade poderá ser um Agente de Saúde especificamente treinado para a atividade.

b) Pré-consulta: É o preparo do lactente para a consulta de Enfermagem.

Composição:

- recepção do cliente;

- identificação do cliente (nome, sexo, idade e filiação);

- verificação de peso, estatura e temperatura;

- verificação de perímetro cefálico;

- encaminhamento para a consulta de enfermagem.

Concentração:

- 12 pré-consultas por criança, isto é, antes de cada consulta.

Elemento nuclear:

- estudante de enfermagem ou agente de saúde.

Rendimento instrumental:

- 06 pré-consultas por hora.

c) Consulta de enfermagem: É a atenção periódica dispensada ao recém-nascido e lactente de risco comum pela enfermeira, visando atender as necessidades de saúde, que dispensam a participação médica.

Composição:

- recepção do cliente.

- estudo prévio do prontuário;

- coleta de informaçōes sobre o parto e período neo-natal

- observação e inspeção física, e anotação no gráfico estatoponderal;

- identificar anormalidades;

- estabelecer esquema de vacinação;

- identificar contra indicação e adiamento da vacinação;

- orientar quanto a importância da vacinação;

- orientar em relação a problemas identificados e à situação encontrada (enfatizar alimentação, aleitamento materno, hábitos de higiene, etc.);

- pesquisar o desenvolvimento psicomotor, de linguagem e social;

- orientar quanto à estimulação adequada (estimulação precoce);

- marcar a consulta subseqüente;

- encaminhar, caso seja necessário, para outros serviços (médico, laboratório, vacinação, psicólogo e outros);

- anotar no prontuário as orientações dadas e a situação encontrada.

\subsection{Saúde Nutricional:}

Aspectos gerais da população quanto à saúde nutricional:

- Trabalhos feitos em comunidades, carentes, têm demonstrado que em geral a base da alimentação é o arroz e feijão com muito pouca variedade, e que a população adquire seus gêneros alimentícios na própria comunidade.

Tem-se verificado também a ausência de hortas caseiras sendo geralmente alegado a falta de água e de espaço.

Outro aspecto comum nessas populações carentes é a existência de tabus alimentares relacionados principalmente com período de gravidez, menstrual e estado gripal. 
Rodrigues K.H. e Colaboradoras - A Enfermagem no Projeto de Cooperação Educacional Vila Paranoá. Rev. Bras. Enf.; RS.36: 183 - 192, 1983.

Assistência prestada:

- Como parte do programa da disciplina Nutrição em Saúde Pública, foram efetuadas visitas à sede da LBA no Paranoá, visando um primeiro levantamento das condições locais. Os projetos da LBA desenvolvidos junto à população foram conhecidos, dando-se ênfase a descrição do componente nutrição em cada um deles (Casulo, PCA, etc...).

3.5. Pesquisas Propostas e em Andamento:

- "Padrões alimentares de crianças de 0 a 1 ano na Invasão do Paranoá";

- "Crescimento e Desenvolvimento: fatores que interferem";

- "Utilização de parteiras curiosas como agentes de saúde".

4. Propostas de Algumas Atividades a Serem Desenvolvidas:

4.1. Área de Saúde da Comunidade:

- Identificados os problemas e estabelecidas ás prioridades, se propõe as seguintes atividades a serem desenvolvidas na comunidade com as famílias de acordo com os recursos disponíveis.

Problemas

Atividades a serem Desenvolvidas

Características Ambientais:

- Presença de animais soltos nas ruas.

- Presença de lixo nas ruas.

- Consumo de água contaminada.

Características de Saúde e Educação:

- Escassez de creches para atendimento de lactentes e pré-escolares;

- Esquema de Imunização incompleto.

Características de Lazer:

- Ausência de diversôes planejadas.

Características Alimentares:

- Dieta deficiente no aspecto qualitativo e quantitativo.

- Escassez de conhecimentos dos aspectos relativos a higiene, saúde, educação sexual e planejamento familiar.

4.2. Área de Saúde Materna:

- Estabelecer Programa de Controle e Imunização de animais domésticos.

- Desenvolver campanha de combate ao lixo.

- Desenvolver programa de uso do filtro e cloro.

- Estabelecimento de um Programa de Mães Crecheiras para atender as mães que trabalham fora:

- Estabelecer programas de conscientização das mães.

- Estabelecer "Domingo de Lazer Comunitário".

- Desenvolver programas de "Horta Comunitária".

- Desenvolver programa de Educação para a saúde abrangendo grupos específicos da comunidade tais como grupo de mães, grupo de casais, grupo de jovens, etc.

- Descoberta de novas gestantes de alto risco para orientação e encaminhamento a Serviços de Saúde do D. F.;

- Programar e desenvolver o treinamento de duas parteiras curiosas da comunidade;

- Desenvolver programas educativos para gestantes e mães sobre:

- Higiene pré-natal;

- Preparo para parto;

- Noções de puericultura;

- Planejamentó familiar.

- Desenvolver programas de orientação especial junto a mães sobre planejamento familiar segundo método de Billings. 
Rodrigues K.H. e Colaboradoras - A Enfermagem no Projeto de Cooperação Educacional Vila Paranoá. Rev. Bras. Enf.; RS.36: 183 - 192, 1983.

4.3. Área de Saúde Infantil:

- Identificar entre a clientela atendida as crianças de risco de acordo com os fatores de risco ambiental e propor programas especiais de orientação e acompanhamento destas crianças;

- Programar e desenvolver orientação das mães sobre:

- Higiene corporal;

- Alimentação;

- Imunização;

- Higiene mental.

4.4. Área de Nutrição:

- Desenvolver atividades mais constantes na área do Paranoá visando treinamento e estágio aos estudantes;

- Desenvolver programas de Educação Nutricional para a comunidade;

- Realizar o diagnóstico nutricional da comunidade;

- Participação nos programas integrados envolvendo Cursos de Enfermagem e Nutrição.

\section{ASSISTÊNCIA PRESTADA - SAÚDE MATERNA}

Consultas Realizadas:

\begin{tabular}{l|r|r}
\hline \multicolumn{1}{c|}{ Tipo de Consulta } & No & $\%$ \\
\hline Consulta a gestante: & & \\
- 1. consulta & 140 & 31,0 \\
- Subseqüente & 251 & 55,7 \\
- Consulta a puérpera & 27 & 6,0 \\
- Consulta ao recém-nascido & 27 & 6,0 \\
- Assistência a domicílio & 06 & 1,3 \\
\hline TOTAL & 451 & 100 \\
\hline
\end{tabular}

Encaminhamentos:

\begin{tabular}{l|c|c}
\hline \multicolumn{1}{c|}{ Tipo de encaminhamento } & N. & $\%$ \\
\hline Serviço odontológico (Casa do Ceará) & 02 & 4,5 \\
Consultas em Ginecologia e Obstetrícia (HRAS) e Clínica Médica & 14 & 31,8 \\
Consulta oftalmológica (HDB) & 01 & 2,3 \\
Consulta de Enfermagem à criança & 27 & 61,4 \\
\hline TOTAL & 44 & 100 \\
\hline
\end{tabular}

Atividades de Enfermagem:

\begin{tabular}{l|c|c}
\hline Atividadès & No & $\%$ \\
\hline - Palestras para grupos de gestantes; & 15 & 33,4 \\
- Palestras para grupos de jovens & 02 & 4,4 \\
- Visitas domiciliares a & & 08 \\
- puérperas & 08 & 17,8 \\
- RN & 02 & 17,8 \\
- Outras & 10 & 4,4 \\
- Orientação de planejamento familiar & 45 & 22,2 \\
\hline TOTAL & & 100 \\
\hline
\end{tabular}


Rodrigues K.H. e Colaboradoras - A Enfermagem no Projeto de Cooperação Educacional Vila Paranoá. Rev. Bras. Enf.; RS.36: 183 - 192, 1983.

Exames Laboratoriais:

\begin{tabular}{l|r|r}
\hline Tipo de exames & N. & $\%$ \\
\hline - Tipo sanguíneo & 112 & 20,0 \\
- Fator Rh & 112 & 20,0 \\
- Teste de Coombs & 14 & 2,5 \\
- VDRL & 109 & 19,5 \\
- J. O. Almeida & 86 & 15,4 \\
- Gravindex & 2 & 0,4 \\
- Hematológico & 53 & 9,5 \\
- Protoparasitológico & 26 & 6,6 \\
- Urina - sumário (EAS) & 08 & 4,7 \\
- Urina - pesquisa de proteína & 559 & 1,4 \\
\hline TOTAL & & 100 \\
\hline
\end{tabular}

ASSISTENCIA PRESTADA - SAÚDE INFANTIL

Consultas de Enfermagem:

\begin{tabular}{lcc}
\hline Tipo de Consulta & No & $\%$ \\
\hline 1. Consulta & 72 & 32,4 \\
\hline Consultas subseqüentes & 93 & 41,9 \\
\hline Consultas de emergência & 57 & 25,7 \\
\hline TOTAL & 222 & 100,0 \\
\hline
\end{tabular}

Encaminhamentos:

\begin{tabular}{lrr}
\hline Tipo de encaminhamento & N. & $\%$ \\
\hline Vacinação & 40 & 57,9 \\
\hline Consulta ORL (HPM) & 5 & 7,2 \\
\hline Consulta pediátrica (N. Bandeirante) & 20 & 28,9 \\
\hline TOTAL & 69 & 100,0 \\
\hline
\end{tabular}

Atividades de Enfermagem:

\begin{tabular}{lcc}
\hline & $N^{\circ}$ & $\%$ \\
\hline Aplicação de injeção I.M. & 2 & 4,3 \\
\hline Orientação para estimulação para melhor desenvolvimento & 15 & 31,9 \\
\hline $\begin{array}{l}\text { Distribuição de medicamentos (hidratante oral, } \\
\text { soro fisiológico, antitérmico) }\end{array}$ & 30 & 63,8 \\
\hline TOTAL & 47 & 100,0 \\
\hline
\end{tabular}

\section{CONCLUSÃO}

Após decorridos os primeiros 12 meses do Convênio FUB/LBA, o trabalho até hoje realizado com o propósito de conhecer e analisar as características da comunidade, assim como a assistência prestada à gestante, criança e jovens, foi de grande valor do ponto de vista de ensino, uma vez que 
Rodrigues K.H. e Colaboradoras - A Enfermagem no Projeto de Cooperação Educacional Vila Paranoá. Rev. Bras. Enf.; RS.36: 183 - 192, 1983.

possibilitou desenvolver nos alunos experiências de trabalho com a comunidade e família carentes; por outro lado, com o prosseguimento do projeto esperamos poder em breve atingir as propostas de ação e cobertura a que nos propusemos.

Desta forma estaremos dando aos alunos do Curso de Enfermagem e Nutrição uma visão ampla da realidade do campo profissional que ele poderá atuar no futuro: experiência de comunidade, experiência nos Serviços de Assistência dos Postos de Saúde da Secretaria de Saúde, e experiência hospitalar.

\title{
BIBLIOGRAFIA
}

1. Andrade, M. N.; Lima, M. L. F. - "O Projeto Vitória - A experiência da Universidade Federal de Pernambuco" - Anais do XXX Congresso Brasileiro de Enfermagem - ABEn - Belém, 16 a 22 de julho de 1978;

2. Duarte/Muxfeldt - Saúde Materna, Hospital de Clínicas de Porto Alegre, Porto Alegre-RS, 1976;

3. Nogueira, Maria Jacyra de Campos et al - Manual para o ensino de Enfermagem de Saúde Pública, São Paulo: Sociedade Beneficente São Camilo, 1978;

4. Paim, L; Costa, L. A. T.; Wright, M. G. M. - "As inovações no Ensino Superior de Enfermagem, face a assistência à saúde da população - Possibilidades e Limitações" - Anais do XXX Congresso Brasileiro de Enfermagem - ABEn - Belém, 16 a 22 de julho de 1978;

5. Ministério da Saúde, Secretaria de Saúde Pública, Divisão Nacional de Organização Sanitária, Setor de Enfermagem - Manual para Programação de Penetração Rural - Rio de Janeiro, 1974;

6. Ministério da Saúde, Secretaria Nacional de Ações Básicas de Saúde, Divisão Nacional de Organização de Serviços de Saúde, Manual para Posto de Saúde - Documento Preliminar - Brasília, 1981;

7. Vieira, César Augusto de Barros - "Extensão de cobertura no Brasil: crise e reforma do sistema de saúde" - Anais do XXX Congresso Brasileiro de Enfermagem - ABEn - Belém 16 a 22 de julho de 1978.

\section{POPULAÇÃO DOS ESTADOS DA REGIÃO SUL DO BRASIL E O COMPROMISSO SOCIAL DA ENFERMAGEM COM O IDOSO}

\author{
* Maria de Lourdes de Souza \\ ** Jonas Salomão Spriccigo
}

ReBEn/08

Souza M. L. e Colaborador - População dos Estados da Região Sul do Brasil e o Compromisso Social da Enfermagem com o Idoso Rev. Bras. Enf.; RS, 36: 192 - 199, 1983

\section{RESUMO}

Os autores apresentam considerações teóricas acerca de questões sociais do envelhecimento individual e populacional. Estabelecem comparações entre os grupos etários de menores de 20 anos e maiores de 60 anos, da população do Brasil, destacando os Estad̦os do Rio Grande do Sul, Santa Catarina e Paraná. Referem os conceitos que fundamentam a assistência de enferrnagem e criticam sua prática na assistência ao idoso. Concluem que a enfermagem deve participar do processo de educação so-

* Doutor em Saúde Pública e Professor Adjunto do Departamento de Saúde Pública do Centro de Ciências'da Saúde da Universidade Federal de Santa Catarina.

** Professor Assistente do Departamento de Enfermagem do Centro de Ciências da Saúde da Universidade Federal de Santa Catarina. 